\title{
Patterns of fiber intake among Brazilian adults: perceptions from an online nationwide survey
}

\author{
Maria do Carmo F PASSOS ${ }^{1}$, Maira Libertad Soligo TAKEMOTO² and Luciana S GUEDES ${ }^{3}$
}

Received: 15 October 2019

Accepted: 9 January 2020

\begin{abstract}
Background - Adequate fiber intake is associated with digestive health and reduced risk of several noncommunicable diseases and is recognized as essential for human health (World Health Organization, 2003). The World Health Organization (WHO) recommends a daily fiber consumption of $\geq 25 \mathrm{~g}$, but previous studies observed a fiber intake in Brazil lower than recommended. Objective - We aimed to describe fiber intake among adults in Brazil and also respondents' knowledge and perceptions about their fiber intake. Methods - National online survey with community-dwelling Brazilian individuals. The survey was conducted during September 2018, using an online platform with closed-ended questions. A representative sample of Brazilian internet users stratified by sex, age, socioeconomic status and geographic region was adopted. Sample size was calculated using a $2 \%$ error margin and $95 \%$ confidence interval $(n=2,000)$. Data was descriptively analyzed using measures of frequency, central tendency and dispersion. Results - Sample included 2,000 individuals who were well-balanced in terms of sex (51.2\% female), with mean age of 35.9 years (most represented age group was 35-54 years, 39.6\%) and from all country geographic regions (49.4\% from Southeast). A total of $69.7 \%$ of them consider their usual diet as healthy and $78.4 \%$ reported consuming fibers regularly. Fibers from natural sources are consumed at least once a day by $69.5 \%$ of the sample, while daily fiber supplements were reported by $29.9 \%$. Absence of regular fiber intake was reported by $21.7 \%$ of respondents and the most common reason was "lack of knowledge about fiber sources" (39.3\%). When informed about the food sources of each type of fiber (soluble and insoluble) and asked about the regular intake, only $2.5 \%$ answered that they do not consume any of them regularly (as opposed to $21.7 \%$ before receiving information about specific fiber sources). Conclusion - Our findings indicate that fiber intake in Brazil is probably insufficient with a high proportion of individuals reporting irregular or absent ingestion of fiber sources in their daily lives. Lack of knowledge about fiber sources and fiber types seems to play a role in this inadequate intake, highlighting the need for nutritional education to achieve healthy dietary patterns in the country.
\end{abstract}

HEADINGS - Dietary fiber. Diet surveys. Socioeconomic factors. Health knowledge, attitudes, practice.

\section{INTRODUCTION}

Adequate fiber intake is associated with digestive health and reduced risk of several noncommunicable diseases, and is recognized as essential for human health ${ }^{(1-7)}$. In terms of gastrointestinal (GI) conditions, evidence has suggested that adequate fiber intake has also potential benefits in the management of chronic constipation and irritable bowel syndrome ${ }^{(8,9)}$. Additionally, two systematic reviews with meta-analyses observed that individuals with higher consumption of fibers had a lower mortality rate than those eating less fibers for both cardiovascular causes, cancer and all-cause mortality ${ }^{(10,11)}$. The physiological mechanism that explains the health benefits associated to dietary fibers is not completely understood, but local and systemic effects are expected once fiber intake is a risk factor for markedly diverse conditions ${ }^{(12)}$.

Following the recognition of a global inadequate fiber intake, in 2003 the World Health Organization (WHO) and the Food and Agriculture Organization of the United Nations (FAO) recommended a daily fiber consumption of $\geq 25 \mathrm{~g}$ as a strategy to prevent noncommunicable diseases ${ }^{(13)}$. The Brazilian Ministry of Health adopted this recommendation as stated in the National Nutritional
Guide for the Brazilian Population and also established a target intake of $5 \mathrm{~g}$ per day for children ${ }^{(14,15)}$.

Despite convincing evidence and explicit guidelines from official health agencies and institutions, previous studies have identified an inadequate fiber intake in the Brazilian population. Sardinha et al. $2014^{(16)}$ assessed the fiber availability (grams per day) of Brazilian households using data from a national survey. Authors stated that the general household availability was insufficient (ranging from 9.9 to 21.4 grams per day) and that lower income and rural households presented higher availability than higher income and urban ones. Mattos et al. 2015(17) identified a higher mean daily intake of $24 \mathrm{~g}$ (17 $\mathrm{g}$ insoluble and $7 \mathrm{~g}$ soluble), with higher means for men (29 g) than women $(20 \mathrm{~g})$. Santos et al. $2016^{(18)}$ observed a low proportion of individuals meeting the adequate intake $(2.0 \%)$ and an average daily intake of $13.1 \mathrm{~g}$.

At the same time, previous reports showed that individuals' knowledge about dietary patterns and fiber role in diet are associated with increased fiber intake ${ }^{(19-21)}$. Thus, the present study was designed to describe fiber intake patterns among adults in Brazil and also respondents' knowledge and perceptions about their fiber intake, through a nationwide web-based survey.

Declared conflict of interest of all authors: Passos MCF: Global Advisory Board Member for Takeda, Speaker for EMS, Aché, Mantecorp. Takemoto MLS: Consultant Epidemiologist for Takeda, Abbvie, Astrazeneca, Biogen, and Novartis. Guedes LS: Sr Medical Manager for Gastroenterology at Takeda.

Disclosure of funding: the study was supported by Takeda Pharmaceuticals Brazil.

${ }^{1}$ Universidade Federal de Minas Gerais, Faculdade de Medicina, Belo Horizonte, MG, Brasil. ${ }^{2}$ ANOVA Consultoria em Saúde, Rio de Janeiro, RJ, Brasil. ${ }^{3}$ Takeda Pharmaceuticals Brazil, São Paulo, SP, Brasil

Corresponding author: Luciana S Guedes. E-mail: luciana.guedes@takeda.com 


\section{METHODS}

We performed a cross-sectional analysis of data from a national web-based survey that aimed to describe patters of fiber intake in community-dwelling Brazilian individuals. The survey was conducted from September 14th to 28th, 2018. To recruit a representative sample of Brazilian internet users who were 16 years of age or older, quotas for sex, age, socio-economic status, and geographic region were used. After receiving information about study procedures and agreeing in participating, respondents were presented with questions about demographics and socioeconomic status (using the Brazilian Criteria for Socio-Economic Classification) ${ }^{(22)}$. Fiber intake was self-reported using the following questions: (i) Do you consume fibers in your daily life?; (ii) If yes, with which frequency do you usually consume each source of fibers (natural and supplements)?; (iii) If not, what are the reasons for not consuming?. Additionally, individuals were presented with lists of fiber sources to answer about their usual intake and also about nutritional knowledge, intestinal function and GI symptoms. Thus, our primary outcome was the pattern of fiber intake in terms of consumption prevalence and frequency.

This study was based on results of an opinion survey and, thus, no approval was required from the Research Ethics Committee. Likewise, it was not necessary to sign an Informed Consent Form. However, all procedures performed are governed by ethical standards of the Brazilian Association of Research Companies (ABEP) and of the European Society of Market Research (ESOMAR), in compliance with the International Standard for Quality on Market and Opinion Research - ISO 20252:2006 and the International Standard for Quality Management ISO 9001:2000.

\section{Statistical analyses}

A descriptive approach was adopted using measures of frequency, central tendency and dispersion, thus hypothesis tests or other exploratory methods were not planned. As a descriptive study, hypothesis tests and models were not used in the present analysis. Sample size was calculated using a $2 \%$ error margin and $95 \%$ confidence interval $(n=2,000)$.

\section{RESULTS}

The final sample was comprised of 2,000 individuals, $51.2 \%$ females, with an average of 36 years old. Socio-demographic sample characteristics are presented in TABLE 1.

In terms of fiber intake (TABLE 2), $78.4 \%$ of respondents reported consuming fibers regularly. This proportion was similar for most age groups, with the exception of 55 or more years $(86.0 \%)$. A similar pattern was observed for both male and female respondents. The self-reported usual fiber intake ranged from $75.3 \%$ in the South region to $83.6 \%$ in the North region. The absolute difference in the percentage of individuals reporting fiber intake between the lower (C) and higher (A) income groups was 7.2\% (75.9\% and 93.1\%, respectively).

As observed in TABLE 3, the frequency of individuals reporting absence of fiber intake varied depending on the assessment method. While $21.7 \%$ of respondents informed that they usually do not consume fibers when questioned without any additional information about fiber sources or foods, the frequency markedly decreased when specific foods and sources where mentioned. When presented with a list of foods that are considered fiber sources, individuals
TABLE 1. Sample characteristics.

\begin{tabular}{lcc}
\hline Characteristics & N & $\%$ \\
\hline Age & 446 & 22.3 \\
16-24 years & 548 & 27.4 \\
25-34 years & 792 & 39.6 \\
$35-54$ years & 214 & 10.7 \\
$55+$ & $35.9 \pm 12.7$ & \\
[Mean \pm SD $]$ & & \\
Sex & 976 & 48.8 \\
Male & 1024 & 51.2 \\
Female & & \\
Geographic region & 110 & 5.5 \\
North & 399 & 20.0 \\
Northeast & 175 & 8.8 \\
Midwest & 988 & 49.4 \\
Southeast & 328 & 16.4 \\
South & 58 & 2.9 \\
Brazilian Criteria for Socio-Economic Classification & \\
Class A & 58.1 \\
Class B & 662 & 64.0 \\
Class C & & \\
\hline
\end{tabular}

SD: standard deviation.

TABLE 2. Self-reported consumption of fibers by demographic characteristics.

\begin{tabular}{|c|c|c|}
\hline \multirow{2}{*}{ Characteristics } & \multicolumn{2}{|c|}{ Fiber intake* } \\
\hline & $\mathrm{N}$ & $\%$ \\
\hline Total sample $(\mathrm{n}=2,000)$ & 1.567 & 78.4 \\
\hline \multicolumn{3}{|l|}{ Age } \\
\hline $16-24$ years $(n=446)$ & 347 & 77.8 \\
\hline $25-34$ years $(n=548)$ & 430 & 78.5 \\
\hline $35-54$ years $(n=792)$ & 606 & 76.5 \\
\hline $55+(n=214)$ & 184 & 86.0 \\
\hline \multicolumn{3}{|l|}{ Sex } \\
\hline Male $(\mathrm{n}=976)$ & 760 & 77.9 \\
\hline Female $(n=1024)$ & 807 & 78.8 \\
\hline \multicolumn{3}{|l|}{ Geographic region } \\
\hline North $(\mathrm{n}=110)$ & 92 & 83.6 \\
\hline Northeast $(\mathrm{n}=399)$ & 320 & 80.2 \\
\hline Midwest $(n=175)$ & 137 & 78.3 \\
\hline Southeast $(\mathrm{n}=988)$ & 771 & 78.0 \\
\hline South $(\mathrm{n}=328)$ & 247 & 75.3 \\
\hline \multicolumn{3}{|c|}{ Brazilian Criteria for Socio-Economic Classification } \\
\hline$A(n=58)$ & 54 & 93.1 \\
\hline$B(n=662)$ & 541 & 81.7 \\
\hline$C(n=1280)$ & 972 & 75.9 \\
\hline
\end{tabular}

*Respondents who answered Yes for the question "Do you consume fibers in your daily life?". 
TABLE 3. Self-reported lack of consumption of fibers using different assessment methods.

\begin{tabular}{lcc}
\hline Characteristics & N & $\%$ \\
\hline $\begin{array}{l}\text { Answer to the question "Do you consume } \\
\text { fibers in your daily life?" (No) }\end{array}$ & 433 & 21.7 \\
Answer to the question "Considering the following list of foods, what \\
is your frequency of consumption?" (Never) \\
Nuts and Seeds & 358 & 17.9 \\
Whole Grains & 75 & 3.8 \\
Legumes & 24 & 1.2 \\
Vegetables and greens & 18 & 0.9 \\
Fruits & 12 & 0.6
\end{tabular}

Answer to the question "Considering the two types of fibers (soluble and insoluble) and their listed sources, what type are you able to ingest in your daily life?"*

$\begin{array}{lcc}\text { Soluble fibers } & 821 & 41.1 \\ \text { Insoluble fibers } & 235 & 11.8 \\ \text { Both types } & 895 & 44.8 \\ \text { None } & 49 & 2.5\end{array}$

* Respondents were presented with a list of fibers sources of each type before answering as following: soluble fibers such as fruit pulp, vegetables and legumes; insoluble fibers such as whole grains and fruit peels.

answering that they never consume each specific item ranged from $0.6 \%$ (fruits) to $17.9 \%$ (nuts and seeds). In a similar manner, when fibers were presented segmented by soluble and insoluble forms with a list of sources of each type, the frequency of individuals answering that they do not consume any of them was $2.5 \%$.

Among 433 respondents who answered that they do not consume fibers in their usual life, the most frequent reasons for the absence of fiber intake were "Lack of knowledge about fiber sources" $(39.3 \%)$ and "The costs would be high" (29.6\%), as shown in FIGURE 1.

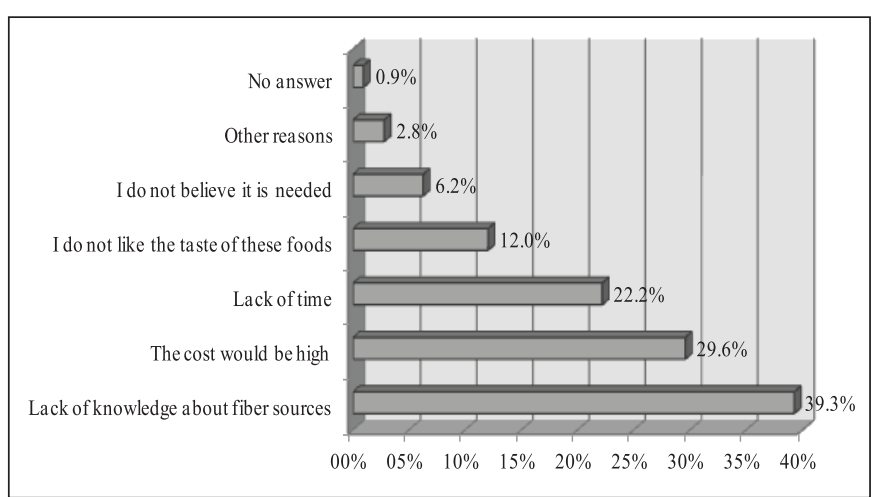

FIGURE 1. Reasons for the absence of fiber consumption $(n=433)$.

TABLE 4 presents the frequency of fiber daily consumption (at least once a day) according to type of source (natural, as presented in foods or fiber supplements) and demographic characteristics. In the total sample, 69.5 and $29.9 \%$ of individuals reported daily consumption of natural sources and fiber supplements, respectively. In numeric terms, natural sources were more frequently reported by those with 55 or more years $(78.3 \%)$, residents in the South region $(74.5 \%)$, and part of the higher income group (A, 83.3\%). Fiber
TABLE 4. Self-reported daily consumption of natural fibers and fiber supplements by demographic characteristics.

\begin{tabular}{lcccc}
\hline Characteristics & \multicolumn{2}{c}{$\begin{array}{c}\text { Daily intake } \\
\text { of natural } \\
\text { sources of } \\
\text { fiber }\end{array}$} & $\begin{array}{c}\text { Daily intake } \\
\text { of fiber } \\
\text { supplements }\end{array}$ \\
\cline { 2 - 5 } & $\mathbf{N}$ & $\%$ & $\mathbf{N}$ & $\%$ \\
\hline Total sample* $(\mathrm{n}=1,567)$ & 1,089 & 69.5 & 469 & 29.9 \\
Age & 230 & 66.3 & 111 & 32.0 \\
$16-24$ years $(\mathrm{n}=446)$ & 290 & 67.4 & 134 & 31.2 \\
25-34 years $(\mathrm{n}=548)$ & 425 & 70.1 & 186 & 30.7 \\
$35-54$ years $(\mathrm{n}=792)$ & 144 & 78.3 & 38 & 20.7 \\
$55+(\mathrm{n}=214)$ & & & &
\end{tabular}

Sex

$\begin{array}{lllll}\text { Male }(\mathrm{n}=976) & 534 & 66.2 & 226 & 29.7 \\ \text { Female }(\mathrm{n}=1,024) & 555 & 68.8 & 243 & 30.1\end{array}$

Geographic region

$\begin{array}{lcccc}\text { North }(\mathrm{n}=110) & 53 & 57.6 & 22 & 23.9 \\ \text { Northeast }(\mathrm{n}=399) & 228 & 71.3 & 115 & 35.9 \\ \text { Midwest }(\mathrm{n}=175) & 85 & 62.0 & 29 & 21.2 \\ \text { Southeast }(\mathrm{n}=988) & 539 & 69.9 & 229 & 29.7 \\ \text { South }(\mathrm{n}=328) & 184 & 74.5 & 74 & 30.0\end{array}$

Brazilian Criteria for Socio-Economic Classification

$\begin{array}{lcccc}A(\mathrm{n}=58) & 45 & 83.3 & 14 & 25.9 \\ \mathrm{~B}(\mathrm{n}=662) & 402 & 74.3 & 172 & 31.8 \\ \mathrm{C}(\mathrm{n}=1,280) & 642 & 66.0 & 283 & 29.1\end{array}$

*Among those respondents who answered yes for the question "Do you consume fibers in your daily life?"

supplements however were less frequent in the 55+ age group and in the A income group. The lower intake of natural sources was observed for the North region $(57.6 \%)$, while fiber supplements were less frequent in the Midwest region. Male and female individuals presented similar pattern of fiber source intake.

Respondents also answered questions assessing their knowledge about fiber intake, diet and intestinal function, as shown in TABLE 5. In the total sample, 69.7\% considered their diet as healthy and $79.2 \%$ classified their intestinal function as regular. $74.2 \%$ and $30.0 \%$ reported that they recognize the role of fiber in regulate intestinal function and the difference between soluble and insoluble fibers, respectively. Gastrointestinal symptoms most frequently informed by subjects with self-reported irregular function were constipation, abdominal bloating and flatulence (TABLE 5). Self-reported frequency of evacuation was at least once a day for $76.0 \%$ of individuals. 
TABLE 5. Self-perception and knowledge about fiber intake, diet and intestinal function aspects.

\begin{tabular}{lcc}
\hline Characteristics & N & $\%$ \\
\hline Rated diet as healthy & 1,394 & 69.7 \\
Rated intestinal function as regular & 1,584 & 79.2 \\
Affirmed to recognize the role of fibers in the & 1,484 & 74.2 \\
intestinal function & & \\
Affirmed to recognize the difference between & 599 & $30.0 \%$ \\
soluble and insoluble fibers & & \\
GI symptoms among those with self-reported irregular intestinal \\
function (n=416) & & \\
Constipation & 318 & 76.4 \\
Abdominal bloating & 281 & 67.5 \\
Flatulence & 269 & 64.7 \\
Abdominal pain & 250 & 60.1 \\
Diarrhea & 104 & 25.0 \\
Hemorrhoids & 1 & 0.2 \\
No answer & 3 & 0.7 \\
Self-reported frequency of evacuation (total sample) & & \\
>1/day & 548 & 27.4 \\
Daily & 972 & 48.6 \\
5 times/week & 183 & 9.2 \\
3 times/week & 167 & 8.4 \\
2 times/week & 84 & 4.2 \\
Weekly & 46 & 2.3 \\
\hline & & \\
\hline
\end{tabular}

\section{DISCUSSION}

The study enrolled a large sample of Brazilian communitydwelling individuals and assessed self-reported fiber intake patterns using a representative sample of Brazilian internet users, as evidenced by geographic distribution and demographic characteristics of the sample, particularly socio-economic status. Our findings indicate that fiber intake in Brazil is probably insufficient with a high proportion of individuals reporting irregular or absent ingestion of fiber sources in their daily lives. Previous studies with Brazilian samples used different methods and outcomes, impairing our ability to make comparisons ${ }^{(16-18)}$. Despite this fact, it is consistent across studies ${ }^{(16-18)}$ that Brazilian individuals do not meet dietary fiber intake targets ${ }^{(13-15)}$ or have low availability of fibers in their diet.

Fiber intake patterns were not homogeneous among sociodemographic subgroups, with higher frequency of any fiber intake among older individuals (over 55 years old), those living in the North and Northeast region and those with higher income. When fiber consumption was assessed according to the type of source (natural or supplements) among those reporting any fiber intake, daily consumption (at least once a day) of natural sources was also more common among those with higher age and higher income, but South region was the one with the highest proportion (and North region had the lowest value). In opposition, daily fiber supplements were less common among older (55+ years) respondents, those living in the North and Midwest region and with higher income.
Male and female individuals presented a very similar pattern. It is important to highlight that this study adopted a descriptive approach and that statistical between-group differences were not tested, thus these observations take into account the numeric differences between individuals presenting each characteristic. As the sample size in our study is large, it is reasonable to believe that these differences are significant, but the observation for the high income group (A) is more prone to bias, due to its relatively small size.

Santos et al. $2016^{(18)}$ also observed a positive effect of higher income and older age in the ingestion of fibers. In an opposite direction, Sardinha et al. 2014 ${ }^{(16)}$ observed higher fiber availability in lower income households and those located in the North and Northeast region. The national Family Budget Research conducted by the Brazilian Institute of Geography and Statistics in 2008-2009 assessed the fiber intake adequacy according to sex and age and observed the prevalence of insufficient fiber intake ranging from $60.0 \%$ among individuals aged $\geq 60$ years to $82.0 \%$ among those with 10-13 years, without relevant differences between male and female individuals (very similar to our findings) ${ }^{(23)}$. As outcomes and exposure variables definitions were marked diverse among these studies and ours, it is difficult to establish comparisons, but it seems that the relationship among income and dietary fiber intake still needs comprehensive evaluation, while the interaction with age and sex seems more well-established in Brazilian reports.

Lack of knowledge about fiber sources and fiber types seems to play a significant role in the observed inadequate intake. Over $20 \%$ of the sample reported absence of fiber ingestion when fiber sources were not listed or mentioned. This percentage was meaningly reduced when lists of foods and fiber sources were explicitly presented and individuals were asked if they usually consume each item, probably indicating that the self-reported absence of fiber consumption is overestimated by individuals' inability to recognize fiber sources in their diet. This is reinforced by the high proportion of individuals affirming that they do not consume fibers because of lack of knowledge about fiber sources or due to financial constraints. Foods and ingredients that are widely available in Brazil and are not considered high-cost, as beans or cassava flour ${ }^{(16)}$, are well-established fiber sources, but our findings may demonstrate that the general population do not see them as rich in fibers. Previous observational studies investigated the impact of individuals' dietary beliefs and nutrition knowledge in the dietary intake and clearly demonstrated an association between these factors ${ }^{(19-21)}$.

In our sample, one in five individuals classified intestinal function as irregular, and a high proportion of those individuals presents significant gastrointestinal symptoms (constipation, abdominal bloating, and flatulence). Our data do not allow a more detailed estimation of constipation prevalence, once the presence of gastrointestinal symptoms was assessed only among those with self-rated irregular intestinal function $(\mathrm{n}=416)$. Nevertheless, at least 318 out of 2,000 respondents $(15.9 \%)$ reported constipation in our sample and this is worth mentioning once fiber consumption is the first line strategy for constipation management in clinical guidelines ${ }^{(24)}$. It is reasonable to affirm that respondents in our sample recognize their constipation but have inadequate knowledge about how to manage this condition, once they do not identify fiber sources in their usual diet or do not ingest them regularly. Our study main limitation is the recall bias risk since fiber intake patterns were self-reported and respondents demonstrated a limited knowledge about fiber sources in their diet. Additionally, our study was not designed to assess adequate intake using objective measures (grams per day, for example) 
or to collect data that would allow comparisons with widely accepted intake targets or with previously published reports on the topic. Despite these limitations, our survey enrolled a large national sample of individuals in the community setting, representative of Brazilian internet users, allowing an overview of fiber intake patterns in the country that seems consistent with previous studies. Future research could further investigate Brazilian individuals' beliefs, expectations and knowledge about dietary fiber intake and also to assess the effectiveness of nutritional education towards healthy diet.

\section{CONCLUSION}

Our findings indicate that fiber intake in Brazil is probably insufficient with a high proportion of individuals reporting irregular or absent ingestion of fiber sources in their daily lives. Lack of knowl- edge about fiber sources and fiber types seems to play a role in this inadequate intake, highlighting the need for nutritional education to achieve healthy dietary patterns in the country.

\section{Authors' contribution}

All authors contributed equally to conceptual planning of this analysis and interpretation of study findings; critically revised and modified the manuscript for relevant intellectual content; and approved the final version to be published. Takemoto MLS conducted data analysis and wrote the preliminary version of the manuscript.

\section{Orcid}

Maria do Carmo F Passos: 0000-0002-5247-9477.

Maira Libertad Soligo Takemoto: 0000-0002-7016-2879.

Luciana S Guedes: 0000-0002-8901-2600.

Passos MCF, Takemoto MLS, Guedes LS. O padrão de consumo de fibras entre adultos brasileiros: percepções de um inquérito nacional online. Arq Gastroenterol. 2020;57(2):144-9.

RESUMO - Contexto - A adequada ingestão de fibras está diretamente associada à saúde digestiva e é reconhecida como essencial à saúde humana (World Health Organization, 2003). A Organização Mundial da Saúde (OMS) recomenda consumo diário de fibras de $\geq 25$ g, mas estudos prévios observaram uma ingesta de fibras no Brasil abaixo do recomendado. Objetivo - Descrever a ingestão, o conhecimento e as percepções sobre o consumo de fibras entre adultos brasileiros. Métodos - Inquérito nacional online com indivíduos brasileiros na comunidade. O inquérito foi conduzido em setembro de 2018, usando uma plataforma online com questões fechadas. Uma amostra representativa dos usuários de internet no Brasil estratificada por sexo, idade, status socioeconômico e região geográfica foi utilizada. O tamanho da amostra foi calculado usando uma margem de erro de $2,0 \%$ em um intervalo de confiança de $95 \%$ (n=2.000). Os dados foram analisados descritivamente usando medidas de frequência, tendência central e dispersão. Resultados - A amostra incluiu 2.000 indivíduos equilibrados em termos de sexo (51,2\% mulheres), com idade média de 35,9 anos (faixa etária mais representada foi 35-54 anos, 39,6\%) e de todas as regiões geográficas do país (49,4\% do Sudeste). Dos respondentes, $69,7 \%$ consideram sua dieta usual como saudável e 78,4\% relataram consumir fibras regularmente. Fibras de fontes naturais são consumidas pelo menos uma vez ao dia por $69,5 \%$ da amostra, enquanto que suplementos de fibras, por $29,9 \%$. O não consumo regular de fibras foi relatado por $21,7 \%$ dos respondentes e a causa mais comum para tal foi "falta de conhecimento sobre fontes de fibras" (39,3\%). Quando informados sobre fontes de fibra de cada tipo (solúvel e insolúvel) e interrogados sobre a ingestão regular, apenas 2,5\% responderam não consumir nenhuma delas regularmente (por oposição a $21,7 \%$ antes de receberem informação sobre fontes específicas de fibras). Conclusão - Nossos achados indicam que a ingestão de fibras no Brasil é provavelmente insuficiente com uma alta proporção de indivíduos relatando consumo ausente ou irregular de fontes de fibras no cotidiano. Falta de conhecimento sobre fontes e tipos de fibras parece desempenhar um papel relevante nesta ingestão inadequada, reforçando a necessidade de educação nutricional para alcançar padrões alimentares saudáveis no país.

DESCRITORES - Fibras na dieta. Inquéritos sobre dietas. Fatores socioeconômicos. Conhecimentos, atitudes e prática em saúde.

\section{REFERENCES}

1. Threapleton DE, Greenwood DC, Evans CEL, Cleghorn CL, Nykjaer C, Woodhead C, et al. Dietary Fiber Intake and Risk of First Stroke. Stroke. 2013;44:1360-8

2. Chiavaroli L, Mirrahimi A, Sievenpiper JL, Jenkins DJA, Darling PB. Dietary fiber effects in chronic kidney disease: a systematic review and meta-analysis of controlled feeding trials. Eur J Clin Nutr. 2015;69:761-8.

3. Chen J-P, Chen G-C, Wang X-P, Qin L, Bai Y. Dietary Fiber and Metabolic Syndrome: A Meta-Analysis and Review of Related Mechanisms. Nutrients 2017;10:24.

4. McRae MP. Dietary Fiber Intake and Type 2 Diabetes Mellitus: An Umbrella Review of Meta-analyses. J Chiropr Med. 2018;17:44-53.

5. Chen K, Zhao Q, Li X, Zhao J, Li P, Lin S, et al. Dietary Fiber Intake and Endometrial Cancer Risk: A Systematic Review and Meta-Analysis. Nutrients. 2018;10:945.

6. McRae MP. The Benefits of Dietary Fiber Intake on Reducing the Risk of Cancer: An Umbrella Review of Meta-analyses. J Chiropr Med. 2018;17:90-6.

7. Ma Y, Hu M, Zhou L, Ling S, Li Y, Kong B, et al. Dietary fiber intake and risks of proximal and distal colon cancers. Medicine (Baltimore). 2018;97:e11678.

8. Shen L, Huang C, Lu X, Xu X, Jiang Z, Zhu C. Lower dietary fiber intake, but not total water consumption, is associated with constipation: a population-based analysis. J Hum Nutr Diet. 2019;32:422-31.
9. Moayyedi P, Quigley EMM, Lacy BE, Lembo AJ, Saito YA, Schiller LR, et al. The Effect of Fiber Supplementation on Irritable Bowel Syndrome: A Systematic Review and Meta-analysis. Am J Gastroenterol. 2014;109:1367-74.

10. Liu L, Wang S, Liu J. Fiber consumption and all-cause, cardiovascular, and cancer mortalities: A systematic review and meta-analysis of cohort studies. Mol Nutr Food Res. 2015;59:139-46.

11. Kim Y, Je Y. Dietary Fiber Intake and Total Mortality: A Meta-Analysis of Prospective Cohort Studies. Am J Epidemiol. 2014;180:565-73.

12. Mcrorie JW, Fahey GC. A review of gastrointestinal physiology and the mechanisms underlying the health benefits of dietary fiber: Matching an effective fiber with specific patient needs. Clin Nurs Stud. 2013;1:82-92.

13. World Health Organization, Food and Agriculture Organization of the United Nations. Diet, nutrition and the prevention of chronic diseases. Geneva; 2003.

14. Brasil. Ministério da Saúde. Guia alimentar para a população brasileira. Brasília; 2014.

15. Brasil. Ministério da Saúde. Dez passos para uma alimentação saudável: guia alimentar para crianças menores de dois anos Um guia para o profissional da saúde na atenção básica. Brasília; 2013

16. Sardinha AN, Canella DS, Martins APB, Claro RM, Levy RB. Dietary sources of fiber intake in Brazil. Appetite. 2014;79:134-8. 
17. De Mattos LL, Martins IS. Consumo de fibras alimentares em população adulta. Rev Saude Publica. 2000;34:50-5.

18. Santos PVF dos, Sales CH, Vieira DAS, de Mello Fontanelli M, Marchioni DM, Fisberg RM. Family income per capita, age, and smoking status are predictors of low fiber intake in residents of São Paulo, Brazil. Nutr Res. 2016;36:478-87.

19. Smith AM, Owen N. Associations of social status and health-related beliefs with dietary fat and fiber densities. Prev Med (Baltim). 1992;21:735-45.

20. Auld GW, Nitzke SA, McNulty J, Bock MA, Bruhn CM, Gabel K, et al. A Stage-of-Change Classification System Based on Actions and Beliefs regarding Dietary Fat and Fiber. Am J Heal Promot. 1998;12:192-201.
21. Królak M, Jeżewska-Zychowicz M, Sajdakowska M, Gębski J. Does Perception of Dietary Fiber Mediate the Impact of Nutrition Knowledge on Eating Fiber-Rich Bread? Nutrients. 2017;9:1255.

22. Associação Brasileira de Empresas de Pesquisa. Critério de Classificação Econômica Brasil 2015. ABEP; 2015 [Internet]. [cited 2019 Jun 18]. Available from: www.abep.org/Servicos/Download.aspx?id=09\&p=cb

23. Instituto Brasileiro de Geografia e Estatítica (IBGE). Pesquisa de Orçamentos Familiares 2008-2009: Análise do Consumo Alimentar Pessoal no Brasil. Rio de Janeiro: IBGE; 2011. 150 p.

24. World Gastroenterology Organisation. World Gastroenterology Organisation Practice Guideline - Constipation. Milwaukee; 2010. 